\title{
PREFACE TO THE AMERICAN EDITION
}

The French edition of this book was published in 2003 as part of the well-known encyclopedic collection Que sais-je? Launched by Paul Angoulvent in I94I, the collection publishes general, popular works on specific subjects, and Les Diasporas bears its hallmarks. When the book came out in 2003, it had very few footnotes, and its main purpose was to present the state of the art on the notion of diaspora and some related elements. Its objective therefore seemed fairly simple. However, starting with my first conversations with the collection editors (in particular Julie Gazier, whom I thank), I insisted on a point I felt was important. I was happy to write the book, because I had already been working on an aspect of the subject for two years. But I felt a certain awkwardness at the idea of writing about "diasporas" (plural) — a title assigned to me by Presses universitaires de France - when I didn't believe in the validity of "diaspora" as a concept. The editors agreed to let me give the text a somewhat schizophrenic character: it would present the state of research being done 
under the "diaspora" heading, while suggesting at another level that the concept may be hiding more phenomena than it reveals.

Three years later, there was no question of returning to these aspects of the text. The book you have in your hands is deliberately and almost proudly schizophrenic. It still attempts to describe the evolution and current content of diaspora studies while, at the same time, taking a sidelong glance at an alternate conceptual framework, especially in chapter 3. Nevertheless, I made a few changes to the original text. Beyond simple corrections of typos and factual errors, the book has undergone two important changes.

First, it now has the backnotes that were absent from the French text because of the Que sais-je? format. The existence of this critical mechanism is a significant evolution, but the book still falls within its intended status and length. Ideally, nearly every line could be developed and made the object of a note, but that is not my goal. The bibliography has been updated, but to keep it from unbalancing the book, I could not cite all the many books and articles that helped me in my writing. I apologize in advance to all those authors who could legitimately demand to be listed. Where possible, statistics have also been updated.

Second, I have been able to include in the American edition some new facts arising from my most recent research. I am currently finishing a habilitation thesis on the usages of the word "diaspora" from the third century в.с. to the present. The book belongs in the lineage of the very few studies dedicated to some or all of the history of the emergence of the notion of diaspora. ${ }^{1}$ When considering an American edition, it seemed important to introduce some new facts about the word's history: the early use of "diaspora” by Robert E. Park in his reading of Simon Dubnov's entry in the Encyclopedia of the Social Sciences in the early I93os; and the discovery of written 
occurrences in French and English of such expressions as "Black diaspora," “African Diaspora," and "Negro diaspora," as early as the I950s and early I96os, whereas specialists in the subject-including me-thought these terms had not appeared in print until I965. In any case, it was impossible to add more facts on the history of the usage of the word as such without completely rewriting the book. Let us hope that the work I am now finishing will one day be available to the public.

A comparative study requires coverage of themes and topics on which one is not an expert, and makes relying on specialists all the more necessary. On many points, I owe a great deal to my exchanges with Francis Abiola Irele, Valérie Amiraux, Jean-Loup Amselle, Martin Baumann, William Berthomière, Michel Bruneau, Christine Chivallon, James Clifford, Robin Cohen, Dana Diminescu, Paul Gilroy, Nancy L. Green, Stuart Hall, Sari Hanafi, Robert Hettlage, Martine Hovanessian, Theodor Ikonomu, Christophe Jaffrelot, Riva Kastoryano, Martin Kilson, Jean-Baptiste Meyer, Eva $\emptyset_{\text {stergaard- }}$ Nielsen, Orlando Patterson, Sergio Della Pergola, Carine PinaGuerassimoff, Roland Robertson, Chantal Saint-Blancat, Saskia Sassen, Gabriel Sheffer, Anne de Tinguy, Khachig Tölölyan, Shmuel Trigano, Johannes Tromp, William Turner, Lina Venturas, Roger Waldinger, Patrick Weil, and Andreas Wimmer.

I also thank my third-and fourth-year students at the University of Paris X-Nanterre, as well as those who took my "Diasporas" and Trans-state Identities class at the Ecole des hautes études en sciences sociales between 2005 and 2007 . I often "tested" new leads and new hypotheses on them. Their questions, criticisms, and occasional confusion helped me reformulate, refine, or jettison my ideas.

The publication of this book abroad would not have been possible without the confidence of Roger Waldinger, the sharp but 
always kind eyes of James Clifford and Andreas Wimmer, and the availability and human qualities of Naomi Schneider of the University of California Press. Its passage into English would have been impossible without the competence, accuracy, and patience of William Rodarmor. They all have my gratitude.

Finally, while writing is often solitary, it becomes meaningful only when done in company. This book owes everything to the presence, love, and patience of my wife, Valérie, and my daughter, Clara, and I dedicate it to them. Je vous aime.

Saint Leu la Forêt, January 2007 